\title{
Investigating the Effectiveness of Media Research on Noticing Media Effects: A Multiple Case Study
}

\author{
Osman Y1lmaz Kartal ${ }^{1, *}$ \\ ${ }^{1}$ School of Education, Çanakkale Onsekiz Mart University, Çanakkale, Turkey \\ *Correspondence: School of Education, Çanakkale Onsekiz Mart University, Çanakkale, Turkey. Tel: \\ 90-533-046-2509. E-mail: oykarta179@yahoo.com
}

Received: July 15, 2018

Accepted: August 2, $2018 \quad$ Online Published: August 24, 2018

doi:10.5430/wje.v8n4p159

URL: https://doi.org/10.5430/wje.v8n4p159

\begin{abstract}
Pre-school education is carried out during a developmental period in which children are vulnerable and dependent on cognitive and affective aspects. In this period, the media is being used at a remarkable level in the formal and informal educational life of children. As a result of their interactions with the media, children are exposed to both positive and negative impositions of the media. Teachers are one of the stakeholders with professional responsibilities that should support children in the face of media impositions. Teachers need to have a high level of awareness of the influence of the media. In the study, the effectiveness of media research on the level of awareness of preschool teachers' media influence is examined. The study was carried out with multiple case studies. Different media researches were conducted on 6 different cases. Pre-school prospective teachers who conduct media research state that media research is quite effective in recognizing the media effect. They emphasize that media should be used consciously in pre-school education practices and media should not be used without conducting media researches.
\end{abstract}

Keywords: media research, media effect, media education, media awareness, pre-school education

\section{Introduction}

When examining the quality of life or standards of the years of 2010, it would not be wrong to say that the media is at the center of the habits of the individual. At all ages, individuals are in intense interaction with the media. This raises the risk of individuals being exposed to positive and negative media imposition. The risk to individuals "who are equipped against the media" falls to a minimum level, while the level of the individuals" who are not equipped to the media" is at the maximum level. One of the media users with poor equipment is children who are in pre-school age period. Media is used extensively in formal and informal educational practices for the pre-school period. Therefore, individuals who are responsible for their children's education need to be conscious of media use. In addition, there is a need for practical applications to gain this consciousness. Media research (MR) has the potential to be effective in the development of media consciousness. Therefore, the level of this potential should be examined.

\subsection{Media Effect and Media Research}

In parallel with the development of information technologies, the communication channels between the media sector and the receivers differ; this differentiation also affects and changes the media culture (Gripsrud, 2002; Kellner, 2003; Leidner and Kayworth, 2006). It is necessary to be able to recognize the changes in the media culture at the functional level and to analyze the parameters emerging / strengthening / disappearing in parallel with this change. One of these parameters is ideology. It is understood through research that ideologies are a construct that builds cultural construction, as it can occur naturally or artificially within a cultural structure (Ault, Ness, Taylor, Johnson, Connelly, Jensen and Dunbar, 2017; Bruce, 2017; Melki and Pickering, 2014; Photikanit and Sirasoonthorn, 2018; Tahir, 2010). When the effects of ideologies on society and culture are taken into account (Oliga, 1995), the following question arises from Oliga's point of view: Are the ideologies that give or shape a cultural character are created by social engineers, media authorities, masters of knowledge, etc.? Or is it through the collective reasoning created by the individual? Individuals have to take into account the influence of the media on themselves. It is a fundamental requirement for media users to be aware of the power of the media on communities' genetic codes, such 
as the formation of meaning and value, the control of emotions, and the perception of culture (Corner, 2016). However, it is not a practical practice to raise awareness of the influence of ideologies created through the media on culture. Therefore, there is a need for functional and sustainable methodologies to activate the decisive role of media users in culture. In this context, MR, which mediates the effects of media on the parameters that construct the society and mediates the interaction with these parameters, appears as an effective methodology (Jensen, 2002; Wimmer and Dominick, 2011). When the literature on MR is examined, studies draw attention to the importance of research that examines the influence of the media on individuals (Cavill and Bauman, 2004) and analyzes the effectiveness of the media in the teaching process (Allen, 1971; Greenhow, Robelia and Hughes, 2009), and also suggestions on the nature of media research (Hjarvard, 2012; Macnamara, 2005; Reese, 2001). With media research highlighting, the question of who will carry out these researches comes to the forefront.

\subsection{Teacher as a Researcher}

The gap between educational research and practice is one of the educational problems of the years 2010's. Educational stakeholders (teachers, school leaders, intermediaries) and researchers emphasize that cooperation between them needs to be strengthened (Vanderlinde and Braak, 2010). However, the quantitative and qualitative complexity of the education system has the potential to prevent / reduce the closure of the research-application gap even with the targeted cooperation. Moreover, it is understood that there are problems in educational researches such as poor educational research, inability to address the field, inefficient guidance in policy or practice (Levin, 2004). Therefore, there is a need for alternative policies as well as for the cooperation initiatives expressed. One of the suggestions developed in the face of this problem is to gain the role of researcher in teacher qualifications. Due to the fact that the gap between education researches and classroom practices widens, it is necessary for teachers to carry out researcher responsibilities in order to make classroom education practices more functional (Grima-Farrell, 2017; Skogh and Veries, 2013). The reason for the need for teachers' researcher identity is that the speed of knowledge production and interaction encompasses educational environments with technology (Kincheloe, 2003). When educational research is taken into account in order to promote the development of knowledge production and instructional practices (Bauer and Fisher, 2007), it is essential to provide functionality in this process. "The teacher as a researcher" approach is considered (Puustinen, Santti, Koski and Tammi, 2018; Smith, Blake, Curwen, Dodds, Easton, McNally, Swierczek and Walker, 2009) and the "research based teacher education" approach is proposed and applied to teacher training programs (Munthe and Rogne, 2015; Puustinen, Santti, Koski and Tammi, 2018). In addition, the value added of the researcher teacher is also examined. There are also studies that show there is a negative relationship between the quality of teaching and the quality of research as well as the studies that show that "teachers that make qualified research" have a high teaching quality (Palali, Elk, Bolhaar and Rud, 2018). In addition, the existence of suggestions for the use of published academic / scientific research results by schools for the purpose of improving learning and teaching (Brown, Zhang, $\mathrm{Xu}$ and Corbett, 2018) reinforces the thesis of active involvement of science and scientific methodologies in educational practice. It is thought that "the teacher as researcher" approach will contribute to overcoming the obstacles encountered in the education process and to capture opportunities. In addition, a strong advantage will be gained in order to guide class based policy (instructional, administrational etc.) through the produced scientific outputs.

\subsection{Media Effect in Pre-School Period}

The pre-school period is a process in which different developmental areas such as cognitive, personality, affective development of the individual are active and the potential to be functional support or obstructive to the development of the child according to the quality of the educational opportunities offered (Balter and Tamis-LeMonda, 2006; Eisenberg, Damon and Lerner, 2006). It is known that social learning is influential when considering the learning activities that mediate the individual's achievements in this development period (Bandura, 1977; Heyes, 2017; Wenger, 2000). It would not be wrong to say that the most effective medium for social learning is the media (Bandura, 2001). In addition, children's interactions with the media tend to increase (OFCOM, 2017, RTÜK, 2013). Interaction with the media can be both an advantage and a disadvantage (Bremer, 2005; Livingstone and Helsper, 2008) in the process of pre-school children's learning by observation behavior (Ma, Heyman, Jing, Fu, Compton, Xu and Lee, 2018; Yussen, 1974). Therefore, the fact that pre-school children are vulnerable to media imposition is a problem to be considered (Villani, 2001). Particularly, it must be considered that the critical media impositions (e.g. identity formation, gender messages, ethnic discrimination, xenophobia, etc.), that can influence developmental periods, are active and strong. This is the most important indication of the seriousness of the situation. In this case, responsibilities of social roles those are in charge of educational support for pre-school children come to the forefront. In these social roles, parents are those who have natural responsibilities and educators / teachers are those who have defined responsibilities. Among the two social roles, pre-school teachers are professional stakeholders with the 
responsibility and equipment to provide professional support to the child (Denham, Bassett and Zinsser, 2012; Katz, 1972; Tschannen-Moran and Hoy, 2001). Pre-school teachers should be equipped with what they can and should do against media impositions either in their educational effectiveness or in their child's daily life activeness (Barnett, 2003; Vodopivec, 2011). In this framework, one of the priority initiatives is to be aware of the effects of the media in the preschool period. The perspectives of pre-school teachers on media content, that children are interacting, will guide the quality of their educational practices. Therefore, any attempt by an educator, who has not done any analytical activity on any media content and has not interpreted the media's power, has been superficial or inadequate in his or her educational support. Preschool teachers must be equipped with MR and must have MR skills in order to develop strategies against media influences both in their educational effectiveness and in their children's non-school activities is a necessity in the reality of the 21 st century. It is expected that pre-school teachers will be aware of media researches and media imposition that penetrate children.

\subsection{Problem Statement}

It is understood that there has been always a need for investigating the influence of the media on preschool children not only before the 2010 but also in the years of 2010 (Siibak and Vinter, 2014; Wartella and Reeves, 1985). The use of media in pre-school education is also increasing (Lee, 2015; Lieberman, Bates and So, 2009; Zaranis, Kalogiannakis and Papadakis, 2013). The educators must be careful about the positive and negative effects of the media. Educators need to understand the media well in order to keep media interaction at a healthy and functional level on behalf of children. In this context, it is thought that media researches (MRs) will have an effect on educators' understanding of the media. In this research, it is examined whether media research is effective in the perceptions of preschool teacher candidates regarding media influence.

\section{Method}

\subsection{Research Design}

The study is a qualitative research and it is realized in a multiple case study design. Case study research is "an inquiry that focuses on describing, understanding, predicting, and/or controlling the individual (i.e., process, animal, person, household, organization, group, industry, culture, or nationality)" (Woodside, 2010, 1). The change in perceptions of preschool teacher candidates, who conducting MR, on the media effect is examined. In this context, the research cases identify the problem situations of the media researches carried out. The problems of the media researches that are carried out determine the research cases. Yin (2003) proposes a multiple case study to provide external validity. In this direction, the research is carried out through 6 different media researches. In the research, media research (MR) is defined as "the study of the investigation of effects of various media applications and media tools on psychological, social, physical, cognitive, etc.".

In the study pre-school teacher candidates were assigned as 6 groups and each group was given media research problem related to pre-school period. Each group carried out their research based on scientific research principles and the research was conducted in about 10 weeks. The media research themes that describe the cases of the groups are as follows

\section{- $\quad$ Case A}

Research title: Gender messages in cartoons.

Research content: A section from all over the cartoons in cartoon channels (TRT Çocuk TV, Cartoon TV, Yumurcak TV) broadcasting in Turkey were examined. Gender messages in cartoons were analyzed.

- $\quad$ Case B

Research title: Values in animated films.

Research content: 5 of the animated films that have made high box office revenues in the last 10 years were examined. The imposition levels of "values" in these films were examined.

\section{- $\quad$ Case C}

Research title: Is the smart signs system really smart?

Research content: National channels broadcasting in Turkey were taken into account. Five TV programs, which were broadcast on these channels and decleared or thought to be appropriate for children, were examined. Whether these programs are appropriate for children was indicated by the "Smart signs system". Participants analyzed content and messages that may be inappropriate for children in these programs. Note: The "smart signs system" specifies which programs the viewer can watch at which age range. 


\section{- $\quad$ Case D}

Research title: The role of computer games in the children's "imagination - violence" tendencies.

Research content: 20 games are selected from the game sites (www.friv.com, www.oyunkral.com, www.oyunlar1.com). Participants played the designated games and conduct their examinations. The potential of games to influence children's fantasy worlds and violence tendencies were analyzed.

\section{- $\quad$ Case E}

Research title: The power of the media on society's family and child perception.

Research content: Family serials (TV) were selected from 1990, 2000 and 2010 years. Participants watched the three parts of the series and performed their examinations. The change in family and child emphasis between each decade is analyzed.

- $\quad$ Case F

Research title: What kind of "individual" profile does the media offer the child?

Research content: National and international cartoons presented in children's channels are examined. By analyzing the "individual" profiles in these cartoons, the "individual" perception that was tried to be formed in the child was examined. Whether there were any differences between national and international cartoons was examined.

In the study, all the processes were followed up in weekly meetings with the researcher in order to make the participants' media research sufficiently. After the 10-week research period, participants presented MR reports. After the media research reports, each group member participated in the data collection phase of the study by filling in the individual interview form.

\subsection{Participant (Subject) Characteristics and Sampling}

Purposeful sampling technique (Suri, 2011) was conducted to identify the participants. As MR has been conducted in the cases, it has been determined that the participants have sufficient knowledge and skills in scientific research. Teacher candidates who have taken courses in Scientific Research Methods and Research Projects in the Preschool Teaching Department have joined the list of participants. 32 teacher candidates who have successfully completed their theoretical and practical training on Scientific Research Methods, Research Projects courses from this list participated in the research according to the volunteer principle. The research was conducted on 6 cases. 32 prospective teachers were divided into groups according to the cases. The distribution of the participants to the groups is given below.

- Case A: 7 prospective teachers (5 female, 2 male)

- Case B: 6 prospective teachers (6 female)

- Case C: 6 prospective teachers (6 female)

- Case D: 3 prospective teachers (3 female)

- Case E: 3 prospective teachers (3 female)

- Case F: 4 prospective teachers (4 female)

\subsection{Data Collection Tool}

A semi-structured interview form consisting of two open-ended questions was used in the study. Interview questions set out within the scope of the research are presented to the expert for content validity. After the suggestions of the experts, the updated interview questions were presented to 5 preschool prospective teachers in terms of clarity (for reliability). After the feedbacks from prospective teachers, the need for probes was examined and the final form was given to the interview form. The interview form is answering the questions listed below.

- $\quad$ Did the MR make a difference in your thoughts on the influence of the media on the children in the pre-school age range?

- As a result of MR, will there be a change in your approach and preferences for using media in preschool education?

\subsection{Data Analysis Techniques}

Analysis of the data in the study was carried out with the qualitative analysis program Maxqda2018. The coding of the data was carried out under 3 themes within the scope of the research purpose. The first is the code that indicates the participants' perceptions of the media effect before the MR. The second is the code that indicates the views of the 
participants about the MA effect on the analysis of the media effect. The third is the code that indicates the tendency to use media in pre-school education after MA. Abbreviations and code maps for themes and codes are presented below.

Table 1. Abbreviations and Code Map

\begin{tabular}{ll}
\hline \multicolumn{1}{c}{ Themes } & \multicolumn{1}{c}{ Codes } \\
\hline PMEbMR: Perception of Media Effect before & NA: No Answer \\
Media Research & PME: Positive Media Effect \\
& MNME: Minimal negative media Effect \\
& NME: Negative Media Effect \\
& N-NME: No Negative Media Effect \\
\hline & MRnE: MR is not effective. \\
& MRLE: MR is less effective. \\
& MRME: MR is moderately effective. \\
& MRVE: MR is very effective. \\
& MRSE: MR has supportive effect. \\
& MnU: Media should not be used \\
TUMaMR: Tendencies to Use Media after MR & MUC: Media should be used consciously. \\
& N-NMR: No need MR \\
& MnUwMR: Media should not be used without MR. \\
\hline
\end{tabular}

In order to provide inter-coder reliability, the results of the researcher's analysis were compared with a different researcher's analysis. Inter-coding reliability coefficients were calculated (Miles and Hubermann, 1994). The inter-coder reliability coefficient was calculated as 0.95 . It is understood that data analysis is reliable.

\section{Results}

The research examines whether MR has any effect on the perception of media effect. In this context, the media effect on children in pre-school age has been discussed. The study in which preschool prospective teachers were included was conducted over 6 cases and the findings were obtained from the results obtained from these cases.

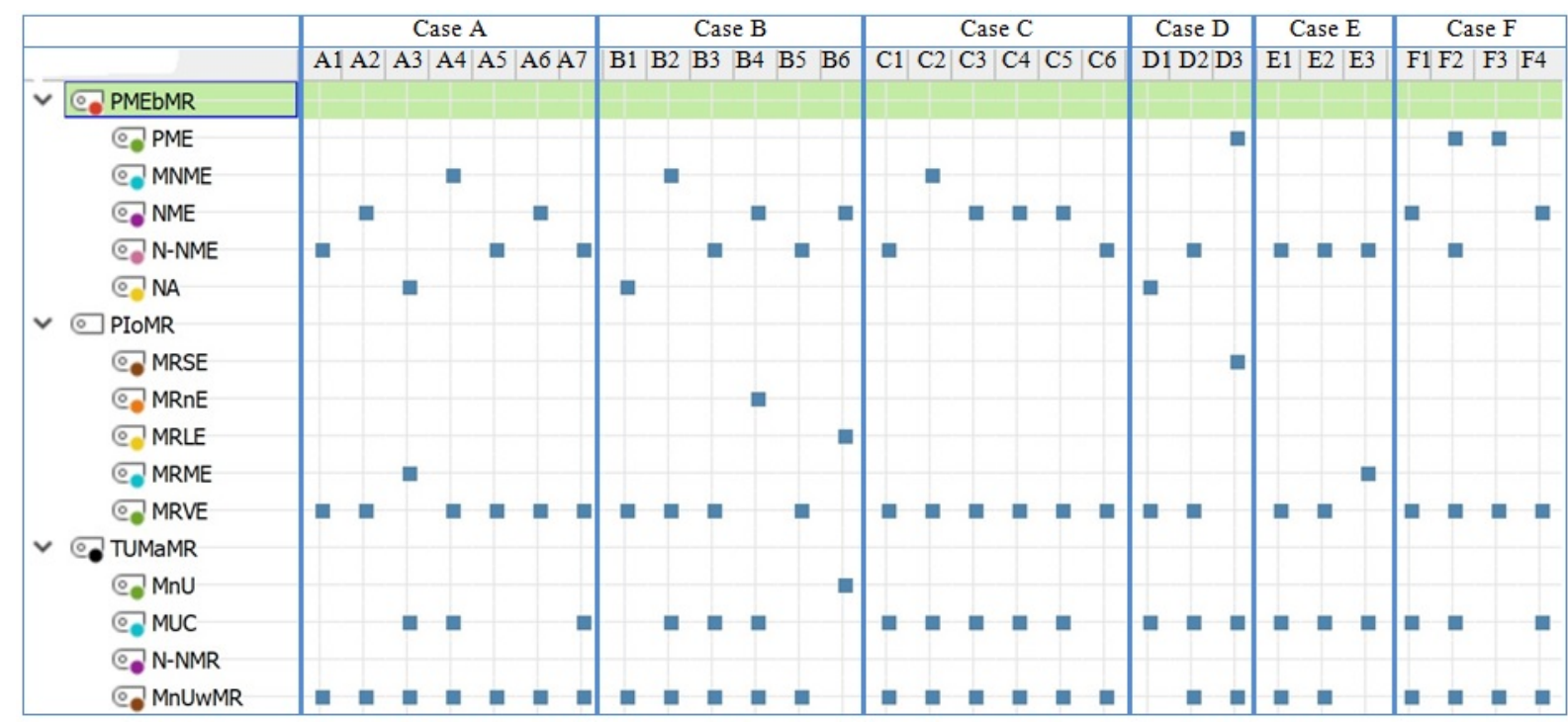

Graph 1. Case-Code Distributions 
In Graph 1, the analysis of 6 cases is presented on a per participant basis with code distribution by theme. The analysis of each case is supported by the "single case model with code hierarchy" presented in Annex 1.

When the cases were examined, it is seen that the participants' perceptions of the media effect before the MR (PMEBMR) are varied. In each case, there are opinions that indicate that the media effect on children is minimal (MNME), negative (NME), and that the media have no negative effect on children (N-NME). There are also participants who say that there is a positive effect of the media (PME). Three participants do not answer (NA) either. The results of the preschool prospective teachers regarding the perceptions of the media effect are striking. It is a pedagogical reality that children are not very strong in cognitive and affective terms and that they are vulnerable to the media. Therefore, preschool teacher candidates had to be aware of the effects of media on children. The presence of participants with assumptions about the negative impact of the media on children in each case indicates that the media is an effective power not only on children but also on prospective teachers.

This study, in which the effect of media research is questioned, is reached in each case as the result that media researches are highly effective (MRVE) in "recognizing the effectiveness of the media" (PIoMR). There is a serious differentiation in the participants' opinions before and after the media research. Participants who thought that the media had no negative effect (N-NME) before the media research (except 1 participant) stated that the media research was very effective (MRVE) in "awareness of the media effect on children". That 1 participant's opinion is that MR is moderately effective (MRME). Participants who thought the media had negative effect (NME) also thought that the media research was very effective (MRVE) (except 1 participant). One participant (in Case B) stated that MR is not effective (MRnE). When the participants' tendency to use media in their pre-school education after the MR is examined, the result is that in each case "the media should not be used without MR" (MnUwMR). Only 1 participant (in Case B) tends to believe that the media should not be used. In addition, the conclusion that the media should be used consciously (MUC) also comes to the forefront.

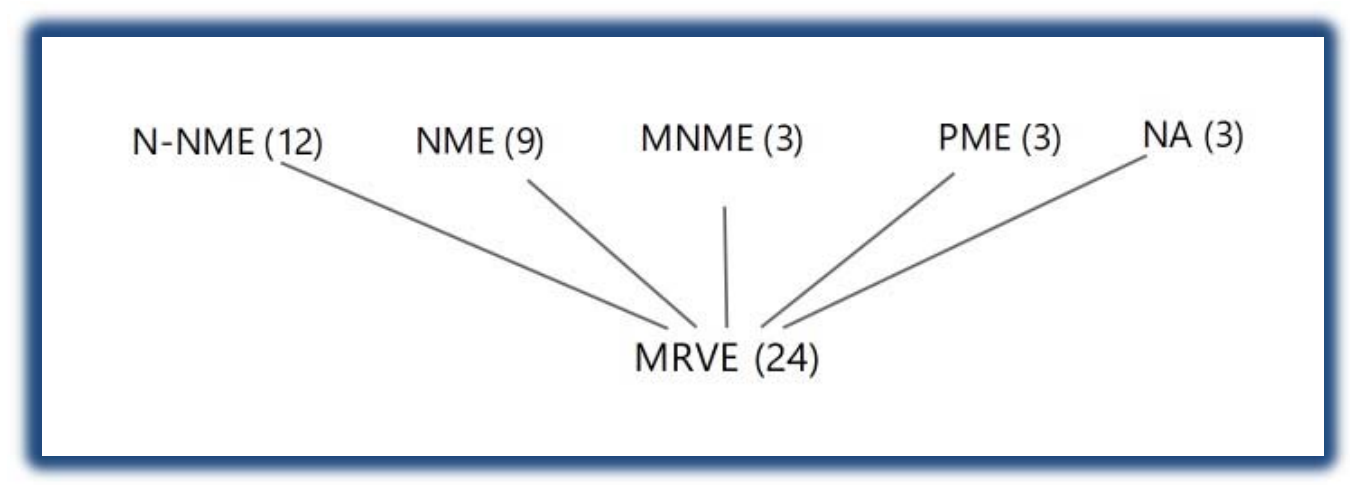

Graph 2. Code-Coexistence Model

When the research purpose is taken into consideration, the most striking result is that MR is very effective (MRVE) in each case. When this outcome is examined from the participants who have different perceptions before the media research, it is helpful to interpret the effectiveness of the MR. It is important to consider that the opinions of preschool prospective teachers who think that the media has not a negative influence on children (N-NME, 12 participants), think that the media has a positive influence (PME, 3 participants), think that the media has a negative effect on minimal level (MNME, 3 participants), think that the media has a negative effect (NME, 9 participants) and do not express any opinions (NA, 3 participants) are "MR high level effective" (MRVE). MR has the power to raise awareness at a remarkable level on individuals who think the media is a positive or negative effect on children.

\section{Discussion}

In the research, the effectiveness of media researches has been examined. Preschool prospective teachers' views on the effect of the media on the children in the pre-school age range were determined and it was researched whether there was any difference in their opinions with the MR. It was seen that there were significant differences in the opinions of preschool teacher candidates who conducted MR on the media effect in the investigations carried out in 6 different cases. In each case, the participants state that their view of the influence of the media on the children in the pre-school age range is severely differentiated. Media research has been a determinant / parameter that significantly 
differentiates the views of participants who have views on the positive or negative impact of the media on children. It is emphasized in the literature that children who are in a cognitive and emotional vulnerable (Balter and Tamis-LeMonda, 2006; Eisenberg, Damon and Lerner, 2006) and foreign-depended period are open to media imposition (Villani, 2001). Preschool teachers, one of the professional roles that are responsible for the education of children (Denham, Bassett and Zinsser, 2012; Katz, 1972; Tschannen-Moran and Hoy, 2001), are creating opportunities or obstacles to media imposition. Considering that the media is being used extensively in preschool education (Lee, 2015; Lieberman, Bates and So, 2009; Zaranis, Kalogiannakis and Papadakis, 2013), teachers' approaches to media use and media research are even more important. In this context, it is an important question whether the media involved in the education of children is an opportunity or a threat (Bremer, 2005; Livingstone and Helsper, 2008). In this context, it is essential for teachers to conduct these inquiries. The most important and practical solution for solving these inquiries is media research (Jensen, 2002; Wimmer and Dominick, 2011). As it is seen in the result of the research, the media research is very effective in recognizing and analyzing the media effects. In addition, it is noteworthy that teacher candidates have differentiated their tendencies towards media use during the education process. Teacher candidates conducting media research are emphasizing that media should not be used without conducting media research. They also state that the media must be used consciously.

\section{Conclusion}

The effect of the media on the users/audiences can not be denied. Regarding to both positive and negative effects, the effects of media on children are stronger than those of other age groups. In this case, negative media imposition can cause irreparable harm to the child users/audiences. When considering the reality of socialization in today's world approaching the 2020s, keeping children away from the media means depriving the child of their some developmental and educational opportunities. In this framework, the investigation of the media that conveys/contains negative media effects appears as a solution instead of keeping the children away from media. This investigation is also defined as media research. In this study, it has been concluded that the media research is an effective method to recognize/notice the media effects. Media content that children interact for educational or entertainment purposes, should be investigated by media research and by their teachers responsible for their education. Media contents should be inserted to educational process after doing media research and evaluating according to media research results. Within this context, media research should be seen as an opportunity for preschool education. In this regard, conscious use of media is possible in preschool education.

\subsection{Suggestion}

It is suggested that teachers should conduct media research (Siibak and Vinter, 2014; Wartella and Reeves, 1985), improve media research knowledge and skills, increase awareness of the media (Barnett, 2003; Vodopivec, 2011), and thus be media literate (Kincal and Kartal, 2009), to make preschool children's education more qualified and to protect them from negative media imposition. It is imperative to add media research knowledge and skills to preschool teacher competencies.

\section{References}

Allen, W.H. (1971). Instructional media research: Past, present, and future. AV Communication Review, 19(1), 5-18.

Ault, M.K., Ness, A.M., Taylor, W.D., Johnson, G., Connelly, S., Jensen, M.L., \& Dunbar, N.E. (2017). Ideological lens matters: Credibility heuristics, pre-existing attitudes, and reactions to messages on ideological websites. Computers in Human Behavior, 68, 315-325. https://doi.org/10.1016/j.chb.2016.11.053

Bandura, A. (1977). Social learning theory. Englewood Cliffs, N.J.: Prentice Hall.

Bandura, A. (2001). Social cognitive theory of mass communication. Media Psychol, 3(3), 265-299. https://doi.org/10.1207/S1532785XMEP0303_03

Balter, L., \& Tamis-LeMonda, C.S. (2006). Child psychology. A handbook of contemporary issues (2nd ed.). New York: Psychology Press.

Barnett, W.S. (2003). Better teachers, better preschools: Student achievement linked to teacher qualifications. NIEER Preschool Policy Matters, 2, 1-11.

Bauer, K., \& Fisher, F. (2007). The education research-practice interface revisited: A scripting perspective. Educational Research and Evaluation, 13, 221-236.

Bremer, J. (2005). The Internet and children: Advantages and disadvantages. Child \& Adolescent Psychiatric Clinics, 
14(3), 405-428. https://doi.org/10.1016/j.chc.2005.02.003

Brown, C., Zhang, D., Xu, N., \& Corbett, S. (2018). Exploring the impact of social relationships on teachers' use of research: A regression analysis of 389 teachers in England. International Journal of Educational Research, 89, 36-46. https://doi.org/10.1016/j.ijer.2018.04.003

Bruce, T. (2017). New technologies, continuing ideologies: Online reader comments as a support for media perspectives of minority religions. Discourse Context Media. https://doi.org/10.1016/j.dcm.2017.10.001

Cavill, N., \& Bauman, A. (2004). Changing the way people think about health-enhancing physical activity: do mass media campaigns have a role? Journal of Sports Sciences, 22, 771-790. https://doi.org/10.1080/02640410410001712467

Corner, John. (2016). 'Ideology' and media research. Media, Culture \& Society. 38(2), 265-273. https://doi.org/10.1177/0163443715610923

Denham, S. A., Bassett, H.H., \& Zinsser, K. (2012). Early childhood teachers as socializers of young children's emotional competence. Early Childhood Educ J., 40, 137-143. https://doi.org/10.1007/s10643-012-0504-2

Eisenberg, N., Damon, W., \& Lerner, R.M. (Eds) (2006). Handbook of child psychology (6 $6^{\text {th }}$ ed.). Volume Three: Social, Emotional and Personality Development. John Wiley\&Sons.Inc.

Greenhow, C., Robelia, B., \& Hughes, J. E. (2009). Web 2.0 and classroom research: What path should we take now? Educational Researcher, 38(4), 246-259. https://doi.org/10.3102/0013189X09336671

Grima-Farrell, C. (2017). What matters in a research to practice cycle? Teachers as researchers. Singapore: Springer Science+Business Media

Gripsrud, J. (2002). Understanding media culture. London: Arnold publishers.

Heyes, C. (2017). When does social learning become cultural learning? Developmental Science, 20, 1-14. https://doi.org/10.1111/desc. 12350

Hjarvard, S. (2012). Doing the right thing: Media and communication studies in a mediatized world. N O R D I C O M Review, 33(1), 27-34.

Jensen, K.B. (2002). A handbook of media and communication research qualitative and quantitative research. Routledge.

Katz, L. G. (1972). Developmental stages of preschool teachers. The Elementary School Journal, 73(1), 50-54.

Kellner, D. (2003). Media culture. Cultural studies, identity and politics between the modern and the postmodern. Routledge-Taylor \& Francis e-Library

Kıncal, R. Y., \& Kartal, O. Y. (2009). Medya okuryazarlığı eğitimi. Milli Eğitim Dergisi, 181.

Kincheloe, J. L. (2003). Teachers as researchers, Qualitative inquiry as a path to empowerment. Routledge Falmer, Taylor \& Francis Group.

Lee, L. (2015). Digital Media and Young Children's Learning: A Case Study of Using iPads in American Preschools. International Journal of Information and Education Technology, 5(12), 947-950. https://doi.org/10.7763/IJIET.2015.V5.643

Leidner, D. E., \& Kayworth, T. (2006). Review: A review of culture in information systems research: Toward a theory of information technology culture conflict. MIS Quarterly, 30(2), 357-399.

Levin, B. (2004). Making research matter more. Education Policy Analysis Archives, 12(56).

Lieberman, D.A., Bates, C.H., \& So, J. (2009). Young children's learning with digital media. Computers in the Schools, 26, 271-283. https://doi.org/10.1080/07380560903360194

Livingstone, S., \& Helsper, E. J. (2008) Parental mediation of children's internet use, Journal of Broadcasting \& Electronic Media, 52(4), 581-599. https://doi.org/10.1080/08838150802437396

Ma, F., Heyman, G.D., Jing, C., Fu, Y., Compton, B.J., Xu, F., \& Lee, K. (2018). Promoting honesty in young children through observational learning. Journal of Experimental Child Psychology, 167, 234-245. https://doi.org/10.1016/j.jecp.2017.11.003

Macnamara, J. (2005). Media content analysis: Its uses; benefits and best practice methodology. Asia Pacific Public Relations Journal, 6(1), 1-34. 
Melki, M., \& Pickering, A. (2014). Ideological polarization and the media. Economics Letters, 125, 36-39. https://doi.org/10.1016/j.econlet.2014.08.008

Miles, M. B., \& Huberman A.M. (1994). Qualitative data analysis: An expanded sourcebook (2nd ed.). Calif.: Sage Publications

Munthe, E., \& Rogne, M. (2015). Research based teacher education. Teaching and Teacher Education, 46, 17-24. http://dx.doi.org/10.1016/j.tate.2014.10.006

OFCOM (2017). Children and parents: Media use and attitudes report. Retrieved from https://www.ofcom.org.uk/_data/assets/pdf_file/0020/108182/children-parents-media-use-attitudes-2017.pdf

Oliga, J.C. (1995). Power, ideology and control. New York and London: Plenum Press.

Palali, A., Elk, R.V., Bolhaar, J., \& Rud, I. (2018). Are good researchers also good teachers? The relationship between research quality and teaching quality. Economics of Education Review, 64, 40-49. https://doi.org/10.1016/j.econedurev.2018.03.011

Photikanit, K., \& Sirasoonthorn, P. (2018). Reconstruction of social ideology through the power of music: Case study of Suntaraporn band, Thailand, Kasetsart Journal of Social Sciences, https://doi.org/10.1016/j.kjss.2018.05.003

Puustinen, M., Santti, J., Koski, A., \& Tammi, T. (2018). Teaching: A practical or research-based profession? Teacher candidates' approaches to research-based teacher education. Teaching and Teacher Education, 74, 170-179. https://doi.org/10.1016/j.tate.2018.05.004

Reese, S. D. (2001). Prologue--Framing public life: A bridging model for media research. Framing Public Life: Perspectives on Media and our Understanding of the Social World. Stephen Reese, Oscar Gandy, and August Grant (eds.), pp. 7-31. (Mahwah, N.J.: Lawrence Erlbaum)

RTÜK (2013). Türkiye'de çocukların medya kullanma alışkanlıkları araştırması. 1. Türkiye Çocuk ve Medya Kongresi.

Siibak, A., \& Vinter, K. (2014). "No Silly Girls' Films!” analysis of Estonian preschool children's gender specific tastes in media favourites and their possible implications for preschool learning practices. IJEC, 46, 357-372. DOI 10.1007/s13158-014-0120-y

Skogh, I-B., \& Veries, M. J. D. (2013). Technology teachers as researchers, Philosophical and empirical technology education studies in the Swedish TUFF Research School. The Netherlands: Sense Publishers.

Smith, C., Blake, A., Curwen, K., Dodds, D., Easton, L., McNally, J. Swierczek, P., \& Walker, L. (2009). Teachers as researchers in a major research project: Experience of input and output. Teaching and Teacher Education 25, 959-965. https://doi.org/10.1016/j.tate.2009.06.004

Suri, H. (2011). Purposeful sampling in qualitative research synthesis, Qualitative research journal, 11(2), 63 - 75.

Tahir, M.B. (2010). Creation of ideology through the language of cinema: A feminist discourse study of media education. Procedia Social and Behavioral Sciences, 2, 4592-4596. https://doi.org/10.1016/j.sbspro.2010.03.736

Tschannen-Moran, M., \& Hoy, A. W. (2001). Teacher efficacy: capturing an elusive construct. Teaching and Teacher Education, 17, 783-805.

Vanderlinde, R., \& Braak, J.V. (2010). The gap between educational research and practice: views of teachers, school leaders, intermediaries and researchers. British Educational Research Journal, 36(2), 299-316.

Villani, S. (2001). Impact of media on children and adolescents: A 10-year review of the research. J. Am. Acad. Child Adolesc. Psychiatry, 40(4), 392-401.

Vodopivec, J. L. (2011). Some aspects of teaching media literacy to preschool children in Slovenia from a perception standpoint of teachers and parents. Acta Didactica Napocensia, 4(2-3), 69-78

Wartella, E., \& Reeves, B. (1985). Historical trends in research on children and the media: 1900-1960. Journal of Communication, Spring, 118-133.

Wenger, E. (2000). Communities of practice and social learning systems. Organization, 7(2), 225-246.

Wimmer, R.D., \& Dominick, J.R. (2011). Mass media research. An introduction. Wadsworth Cengage Learning.

Woodside, A.G. (2010). Case study research: Theory, methods, practice. USA: Emerald Group Publishing Limited. 
Yin, R. K. (2003). Case study research. Design and methods. Third edition. Sage Publications.

Yussen, S. R. (1974). Determinants of visual attention and recall in observational learning by preschoolers and second graders. Developmental Psychology, 10(1), 93-100.

Zaranis, N., Kalogiannakis, M., \& Papadakis, S. (2013). Using mobile devices for teaching realistic mathematics in kindergarten education. Creative Education, 4(7A1),1-10. https://doi.org/10.4236/ce.2013.47A1001

Annex 1. Results of Cases - Single Case Models with Code Hierarchy

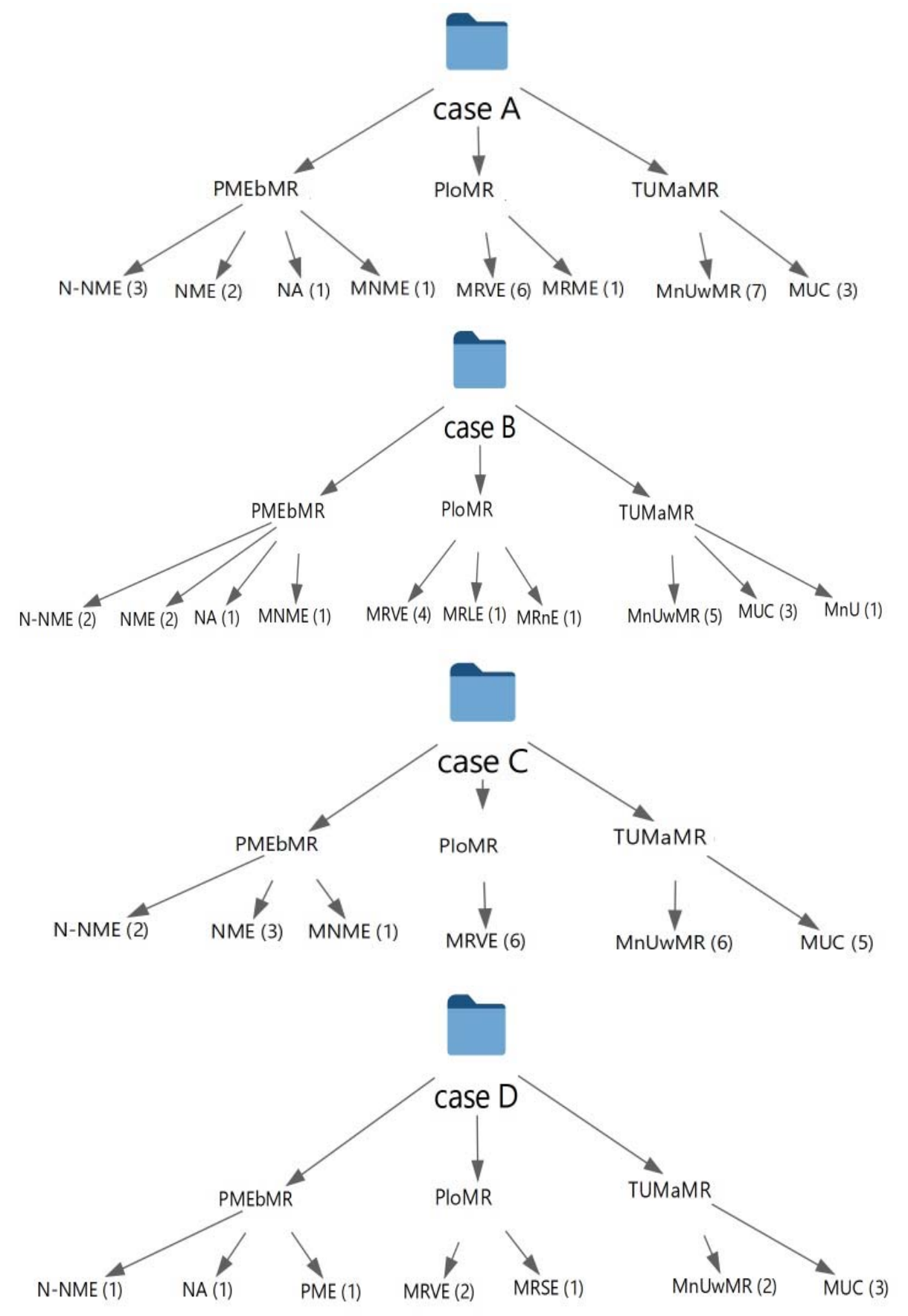



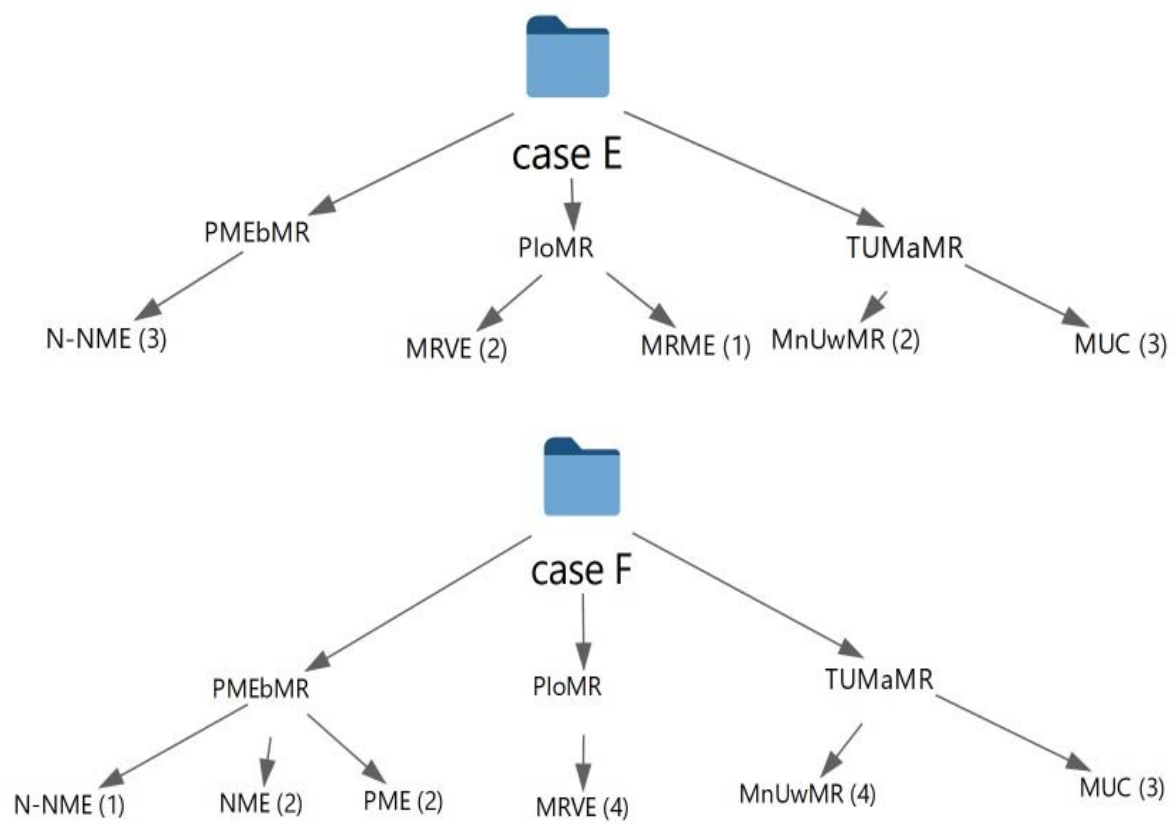